\title{
PENGEMBANGAN SISTEM INFORMASI KERJA PRAKTIK BERBASIS ANDROID UNTUK MAHASISWA DAN DOSEN
}

\author{
Viny Christanti M. ${ }^{1}$ dan Bagus Mulyawan ${ }^{2}$ \\ 1,2 Jurusan Teknik Informatika, Unviersitas Tarumanagara \\ ${ }^{1}$ Email: viny@untar.ac.id \\ 2Email: bagus@untar.ac.id
}

\begin{abstract}
ABSTRAK
Pada saat ini pengelolaan kerja praktik di FTI sudah dilakukan secara komputerisasi berbasis web. Mahasiswa sudah dapat melakukan pendaftaran dan pengisian data KP secara online. Dosen dapat mengisi nilai secara online pada saat sidang. Koordinator KP dapat memantau dan mengawasi proses pelaksaaan KP secara langsung. Namun masih terdapat kendala pada saat sidang KP, dimana dosen kesulitan pada saat harus menginputkan nilai melalui web. Tidak semua dosen membawa laptop ke ruang sidang, sedangkan pengisian nilai melalui browser disamrtphone masih sulit dilakukan karena tampilannya yang kecil. Oleh karena itu, terdapat beberapa permintaan untuk membuat sistem berbasis mobile agar tidak perlu membawa laptop ke ruang sidang. Dalam pengabdian ini, tim PKM akan memberikan kontribusi mengembangkan aplikasi sistem informasi kerja praktik berbasis android dan pelatihan penggunaan aplikasi SIKP FTI tersebut. Aplikasi dibuat dalam bentuk mobile dengan menggunakan android agar dapat digunakan oleh dosen dan mahasiswa. Dosen dapat menginputkan secara langsung nilai sidang pada saat sidang dengan menggunakan smartphone masingmasing dan langsung menandatanganinya. Dosen pun dapat menginputkan catatan atau komentar yang harus dilakukan mahasiswa untuk perbaikan hasil sidang. Mahasiswa pun dapat melihat catatan sidang, jadwal sidang dan data KP melalui smartphone masing-masing.
\end{abstract}

Kata kunci: Android; Sistem Informasi Kerja Praktik; SIKP.

\section{PENDAHULUAN}

FTI Untar adalah fakultas yang memberikan matakuliah berhubungan dengan Teknologi Informasi. Salah satu matakuliah yang wajib ditempuh oleh mahasiswa adalah matakuliah kerja praktik. Pada pengabdian sebelumnya telah dibangun sebuah sistem pengelolaan kerja praktik yang dapat digunakan secara online (Viny et. al, 2017). Sistem tersebut sudah berjalan dan digunakan oleh mahasiswa, dosen, koordinator kerja praktik dan staff prodi. Pada saat menggunakan aplikasi ini user dapat mengaksesnya melalui PC atau laptop. Penggunaan sistem ini melalui PC dan laptop sudah berjalan dengan baik dengan tampilan antar muka yang mudah digunakan.

Namun pada saat sidang, dosen lebih memilih untuk menggunakan smartphone dalam mengakses aplikasi ini. Dosen lebih banyak membawa smartphone dibandingakan membawa laptop yang besar. Aplikasi sistem pengelolaan KP sudah dapat diakses melalui smartphone menggunakan browser apa saja. Namun tampilan aplikasi pada browser akan terlihat kecil dikarenakan memang sistem diperuntukan untuk layar pada PC atau laptop. Sehingga dosen sulit untuk melakukan pengisian nilai dan pengetikan catatan sidang.

Selain para dosen, mahasiswa pun banyak yang meminta untuk dapat mengakses sistem menggunakan smartphone. Selain memudahkan mereka dalam mengupload berkas yang dibutuhkan untuk kelengkapan KP, smartphone pun mempercepat mereka untuk mengisi dan melihat catatan atau pengumuman yang berkaitan dengan KP. Mereka tidak perlu membuka terlebih dahulu PC atau laptop yang pasti membutuhkan tempat dan waktu yang lebih lama. Pengelolaan kerja praktik di fakultas dilakukan oleh koordinator kerja praktik bekerja sama dengan ketua program studi dan diawasi oleh dekan fakultas. Pelaksanaan kerja praktik sudah diatur berdasarkan peraturan dan pedoman yang sudah disiapkan oleh fakultas dan tercantum 
dalam standar dan manual sistem penjaminan mutu internal fakultas (SPMI, 2017). Mahasiswa dapat melaksanakan kerja praktik berdasarkan aturan yang telah dibuat.

Penggunaan sistem berbasis web dirasa semakin meningkatkan quality control terhadap pelaksanaan KP. Beberapa kendala-kendala yang muncul pada penggunaan sistem berbasis web adalah:

1. Tampilan web yang sulit dilihat pada saat membuka melalui smartphone

2. Pada saat sidang dosen sulit mengisi nilai pada web karena tidak membawa laptop atau PC, sehingga pengisian manual masih ada yang menggunakan kertas

3. Dosen sulit menginput komentar mengenai hasil sidang KP.

4. Masih ada dosen yang menggunakan kertas atau mencoretnya saja di buku laporan perbaikan apa yang perlu dilakukan. Hal ini dapat menyebabkan komentar/saran/perbaikan tersebut tidak terdokumentasi dengan baik

5. Mahasiswa ingin dapat melihat komentar dari dosen pada saat sidang dengan mudah tanpa harus membuka laptop terlebih dahulu.

\section{SOLUSI PERMASALAHAN}

Sistem informasi KP berbasis web ini sangat berguna dan perlu dikembangkan dalam bentuk mobile agar setiap pihak yang terkait dapat mengakses dengan lebih mudah. Berdasarkan beberapa hasil analisis masalah yang ada dalam pengelolaan kerja praktik, maka tim PKM mengusulkan untuk membangun sebuah sistem yang berbasis mobile. Sehingga sistem yang ada saat ini dapat disesuaikan agar dapat dijalankan melalui smartphone. Tim PKM akan membuat aplikasi pengelolaan kerja praktik berbasis mobile menggunakan android.

Sistem berbasis android dipilih karena akademisi FTI Untar lebih banyak pengguna smartphone berbasis android dibandingkan IoS. Selain itu aplikasi ini juga dibangun sesuai dengan prosedur kerja praktik yang terdapat dalam SPMI dan sesuai flowchart yang sudah dibuat pada sistem informasi KP berbasis web. Aplikasi pengelolaan kerja praktik ini secara khusus akan dibuat untuk mahasiswa dan dosen FTI yang sudah memiliki login yang diperoleh sebelumnya.

Aplikasi pengelolaan kerja praktik ini dibuat dengan tampilan yang sesuai dengan konsep kebutuhan untuk dosen agar dapat menginput komentar, menginput nilai pada saat sidang, menandatangani nilai sidang. Sedangkan bagi mahasiswa memiliki menu untuk melihat jadwal sidang, melihat pengumuman dan melihat komentar hasil sidang. Pengelolaan kerja praktik dibuat agar memudahkan pihak-pihak yang terkait dalam mengatur dan mengelola kegiatan kerja praktik. Penggunaan aplikasi ini juga dapat memudahkan proses pendokumentasian dan proses pencarian data kerja praktik yang sudah dilakukan oleh mahasiswa.

\section{METODE PELAKSANAAN}

FTI Untar merupakan fakultas yang bergerak dalam bidang ilmu teknologi sehingga sarana dan prasarana yang menggunakan teknologi sangat sesuai dengan kebutuhan pembuatan aplikasi ini. Tim PKM ini juga merupakan tim yang pakar didalam bidangnya. Tim PKM terdiri dari 2 orang yaitu:

1. Ketua tim adalah salah satu dosen yang menjabat sebagai koordinator kerja praktik sehingga mengetahui proses kerja praktik. Ketua tim memiliki kepakaran dalam bidang Information Retrieval dan pembuatan aplikasi web. Ketua tim bertugas merancang, membuat dan memberikan pelatihan kepada mahasiswa dan dosen.

2. Anggota tim adalah pakar didalam bidang web, jaringan dan distributed application. Anggota tim bertugas untuk menyiapkan dan mengimplementasikan program ke 
server. Selain itu anggota tim juga bertugas membantu pelatihan aplikasi kepada pengguna.

Pengabdian ini dilaksanakan dari bulan Februari-Juli 2018. Jadwal kegiatan dapat dilihat pada Tabel 1. Pengabdian dimulai dengan membuat aplikasi SIKP FTI Untar berbasis mobile. Proses pebuatan diawali dengan melakukan persiapan analisis data dan kebutuhan, kemudian dilanjutkan dengan perancangan antarmuka, alur, dan basis data yang akan digunakan oleh dosen dan mahasiswa. Selanjutnya pembuatan program dilakukan selama 2 bulan.

Tabel 1. Rencana Jadwal Kegiatan

\begin{tabular}{lll}
\hline No & Kegiatan & Hari/Tanggal \\
\hline 1 & Persiapan: & Februari 2018 \\
& Menyiapkan sarana dan prasana, analisis permasalahan mitra, pengumpulan data & \\
\hline 2 & $\begin{array}{l}\text { Perancangan: } \\
\text { Perancangan antar muka, basis data, flowchart, program }\end{array}$ & Februari-Maret 2018 \\
\hline 3 & Pembuatan program & Maret-April 2018 \\
\hline 4 & Uji coba oleh tim & April 2018 \\
\hline 5 & Implementasi ke server & Mei 2018 \\
\hline 6 & Pelatihan terhadap pengguna & Mei-Juni 2018 \\
\hline 7 & Pembuatan Laporan & Juli 2018 \\
\hline
\end{tabular}

\section{TARGET LUARAN DAN CAPAIAN}

Pengabdian ini memiliki target utama yaitu hasil aplikasi dapat berguna dan digunakan seterusnya untuk membantu pengelolan KP FTI Untar. Adapun target luaran lainnya yang akan dihasilkan sesuai dengan rencana kegiatan adalah sebagai berikut:

1. Produk berupa aplikasi pengelolaan kerja praktik (SIKP FTI Untar) berbasis android

2. Modul yang berisi cara penggunaan aplikasi tersebut

3. Jasa berupa pelatihan (Training of Trainers) Teknologi Informasi untuk mahasiswa dan dosen pembimbing serta penguji kerja praktik

4. Jurnal yang dimasukan ke jurnal nasional berupa karya ilmiah mengenai tahapan dan hasil pembuatan aplikasi

5. Laporan kegiatan

6. Hak Kekayaan Intelektual (HKI) berupa hak cipta program aplikasi

\section{Produk}

Hasil aplikasi pengabdian ini terdiri dari flowchart yang merupakan alur program untuk dosen dan mahasiswa. Gambar 1 adalah alur program untuk dosen dan Gambar 2 adalah alur program untuk mahasiswa. Dosen memiliki 3 fungsi utama yaitu melihat jadwal sidang, menginput hasil sidang berupa komentar dan nilai dan yang terakhir melihat hasil sidang yang dapat langsung ditandatangani pada smartphone. Sedangkan mahasiswa memiliki 4 fungsi utama yaitu menginput data KP, melihat hasil catatan sidang, melihat jadwal dan memilih jadwal konsultasi. 


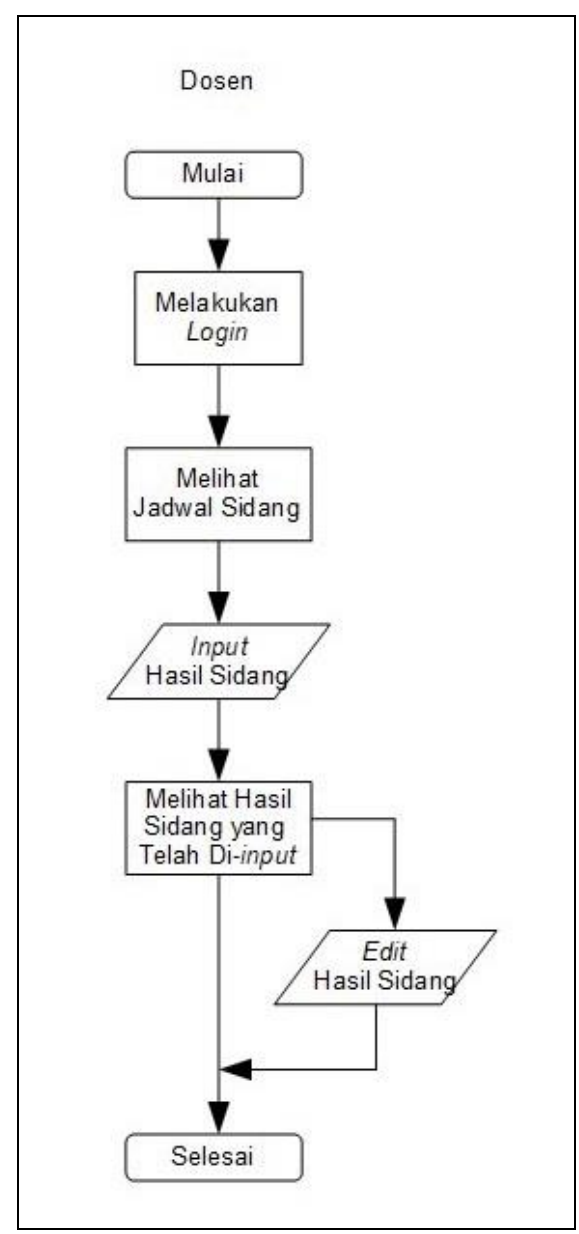

Gambar 1. Flowchart program untuk dosen

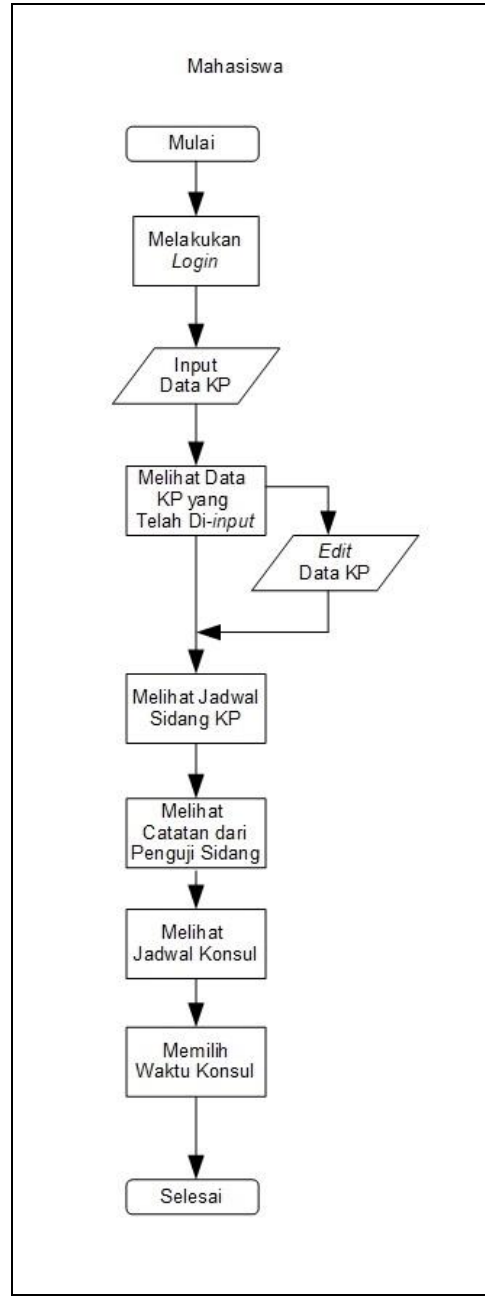

Gambar 2. Flowchart program untuk mahasiswa

Antarmuka hasil program untuk dosen dapat dilihat pada gambar 3-6. Gambar 3 adalah haaman utama aplikasi SIKP FTI pada android. Dosen harus sudah memiliki akun yang sudah ditentukan oleh koordinator KP. Sedangkan gambar 4 adalah tampilan antar muka menu input catatan sidang yang dilakukan pada saat sidang berlangsung. Menu input nilai dan komentar hanya dapat diakses sesuai jadwal sidang masing-masing kelompok sesuai dan hanya dapat dilakukan oleh dosen yang sudah diatur jadwalnya oleh koordinator KP. Gambar 5 adalah menu untuk melihat nilai keseluruhan setelah diinput oleh dosen. Kemudian pada gambar 6, dosen dapat menandatangani hasil sidang secara langsung pada aplikasi SIKP FTI Untar dan dapat langsung dicetak. 


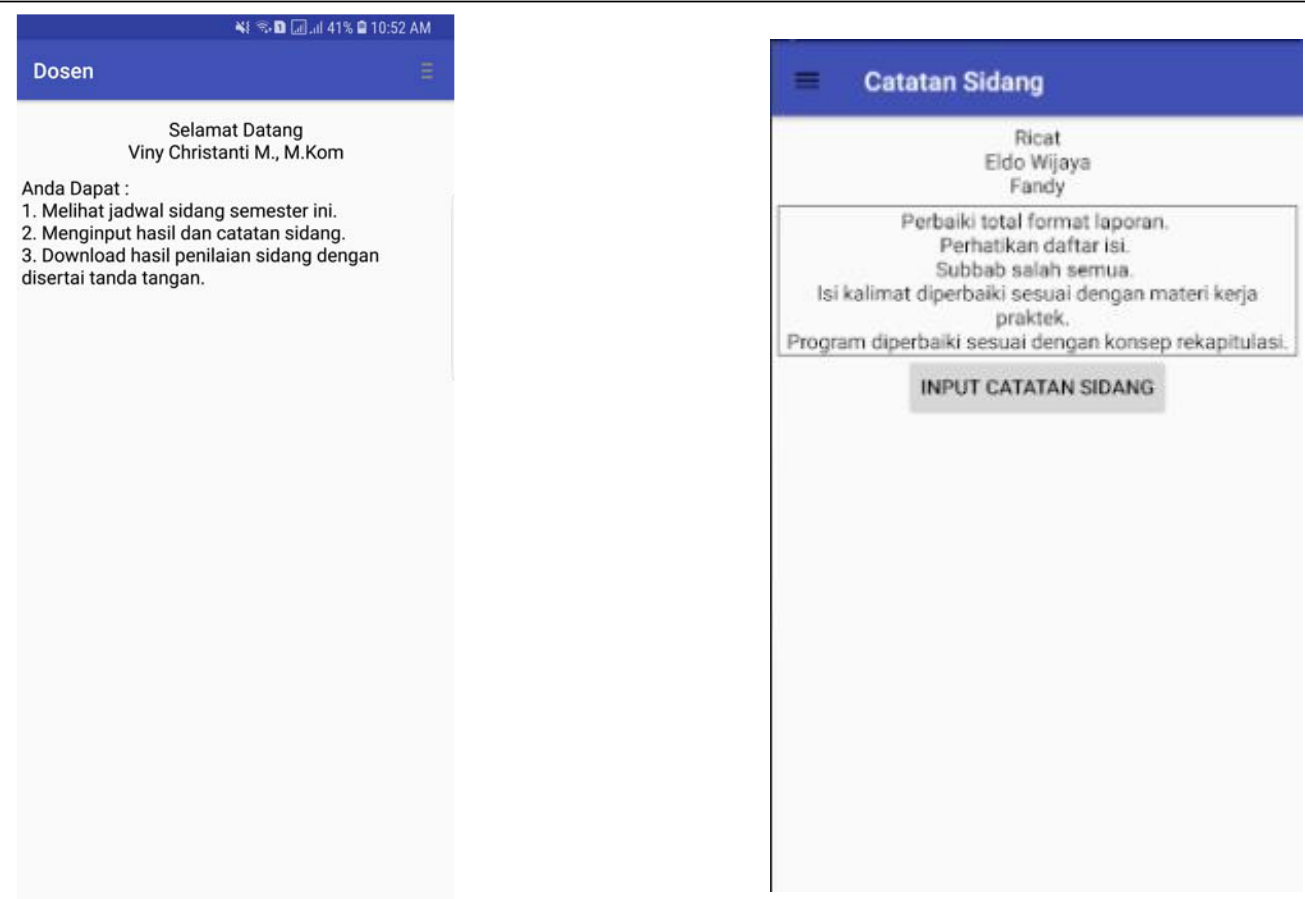

Gambar 3. Antarmuka menu utama dosen

\section{Hasil Sidang}

\begin{tabular}{|c|c|}
\hline \multicolumn{2}{|l|}{$\begin{array}{l}\text { Ricat } \\
\text { Eldo Wijaya } \\
\text { Fandy }\end{array}$} \\
\hline $\begin{array}{l}\text { Sistematika, sikap, dan bahasa yang } \\
\text { digunakan dalam presentasi. }\end{array}$ & 56.00 \\
\hline $\begin{array}{l}\text { Pemaparan laporan dan penguasaan materi } \\
\text { dalam menjawab pertanyaan. }\end{array}$ & 56.00 \\
\hline $\begin{array}{l}\text { Bobot, tingkat kesulitan, dan kecocokannya } \\
\text { dalam bidang Teknologi Informasi. }\end{array}$ & 56.00 \\
\hline Kejelasan dalam menulis laporan kerja praktik. & 56.00 \\
\hline & 56.00 \\
\hline
\end{tabular}

Gambar 5. Antarmuka lihat nilai oleh dosen
Gambar 4. Antarmuka menu input komentar oleh dosen

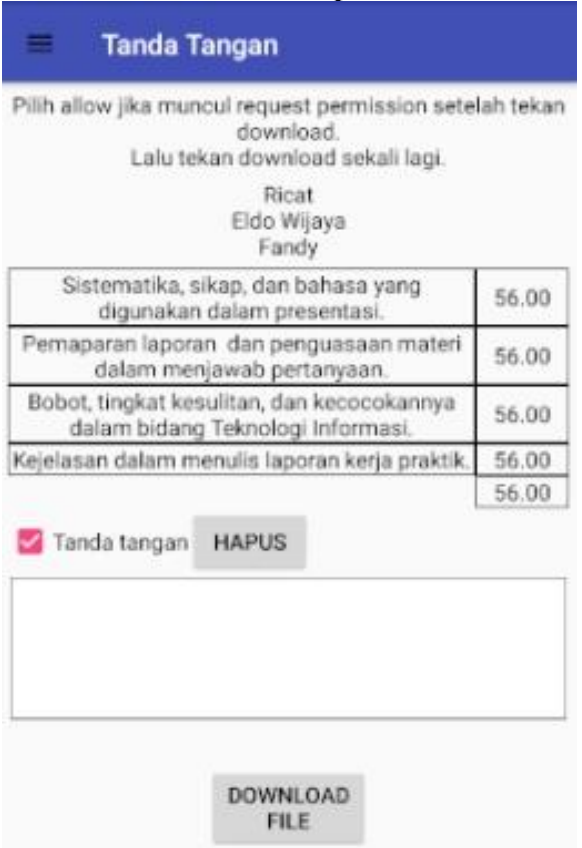

Gambar 6. Antarmuka menu tandangan nilai oleh dosen

Antarmuka aplikasi SIKP FTI Untar dapat dilihat pada gambar 7-10. Menu halaman utama mahasiswa dapat dilihat pada gambar 7, dimana mahasiswa dapat melihat pengumuman terkait jadwal sidang dan pengumuman lainnya. Sedangakan Gambar 8 adalah menu untuk melihat data KP secara keseluruhan dan mahasiswa juga dapat mengedit atau menginput data melalui aplikasi ini. Pada gambar 9, mahasiswa dapat melihat catatan sidang yang berisi apa saja yang perlu diperbaiki dari hasil laporan KP yang sudah dikerjakan. Sedangakan sesudah sidang mahasiswa harus memilih jadwal konsultasi format untuk pemeriksaan terakhir hasil laporan KP yang sudah diperbaiki. 


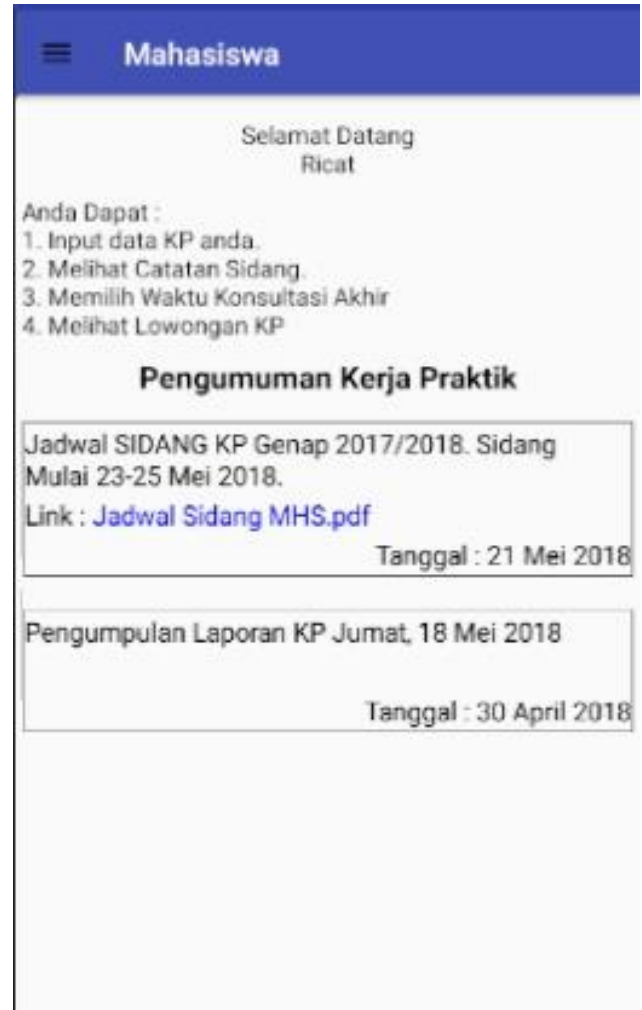

Gambar 7 Antarmuka menu utama mahasiswa

\section{Lihat Catatan Sidang}

Berikut adalah catatan sidang kelompok anda: Perancangan sistem tidak sesuat, database masih salah, program belum berfungsi.

1. Perbaiki typo dan format

2. Perbaiki program (approval lembur)

3. Program belum jadi untuk ijin, sakit, dsb

4. DFD ada ganda

5. Judul berubah

Perbaiki total format laporan

Perhatikan daftar isi.

Subbab salah semua

Isi kalimat diperbaiki sesuai dengan materi kerja

praktek

Program diperbaki sesuai dengan konsep rekapitulasi.

\section{SIMPAN KE FILE.}

File tersimpan di media penyimpanan (internal/external) dengan nama catatan_sidang.txt.

\section{Data KP}

Berikut adalah data KP anda.

\begin{tabular}{l} 
Aplikasi untuk rekapitulasi absensi dan lembur pada PT \\
Mega Akses Persada \\
Viny Christanti M., M.Kom, \\
PT Mega Akses Persada (FiberStar) \\
Picat \\
$\begin{array}{c}\text { Eldo Wijaya } \\
\text { Fandy }\end{array}$ \\
\begin{tabular}{|c|} 
Jadwal Sidang \\
Jumat, 25-Mei-2018 \\
O8.00
\end{tabular} \\
\hline $\begin{array}{c}\text { INPUT DATA } \\
\text { KP }\end{array}$ \\
$\begin{array}{c}\text { CATATAN } \\
\text { SIDANG }\end{array}$ \\
\hline
\end{tabular}

Gambar 8 Antarmuka menu data KP mahasiswa

\section{Jadwal Konsul}

Jadwal konsul kelompok anda:

Hari Selasa, 05-06-2018 Pukul 09:30-00

Klik waktu berwarna biru untuk memilih waktu konsul.

Senin, 04-06-2018

\begin{tabular}{|l|l|r|r|}
\hline \multicolumn{5}{|c|}{ Senin, 04-06-2018 } \\
\hline $09: 00$ & $09: 15$ & $09: 30$ & $09: 45$ \\
\hline $10: 00$ & $10: 15$ & $10: 30$ & $10: 45$ \\
\hline $11: 00$ & $11: 15$ & $11: 30$ & $11: 45$ \\
\hline \multicolumn{4}{|c|}{ Selasa, 05-06-2018 } \\
\hline $09: 00$ & $09: 15$ & $09: 30$ & $09: 45$ \\
\hline $10: 00$ & $10: 15$ & $10: 30$ & 10.45 \\
\hline $11: 00$ & $11: 15$ & $11: 30$ & $11: 45$ \\
\hline
\end{tabular}

Gambar 9. Antarmuka menu catatan sidang

Gambar 10. Antarmuka menu memilih jadwal konsultasi

\section{Pelatihan}

Proses pelatihan kepada mahasiswa dan dosen dilakukan bersamaan program diuji coba oleh tim dan diimplementasikan di server. Proses pelatihan kepada mahasiswa dilakukan pada saat 
kegiatan briefing peserta KP yaitu 30 April 2018. Sedangkan pelatihan kepada dosen dilakukan dengan 2 cara, melalui pengiriman manual kepada dosen dan pada saat sidang KP dilaksanakan yaitu pada tanggal 23-26 Mei 2018. Proses pelatihan terus dilakukan sampai pada saat konsultasi format laporan oleh mahasiswa dan koordinator KP pada tanggal 4-5 Juni 2018.

Pada saat pelatihan, dosen sudah harus memiliki akun yang dapat diperiksa pada web KPFTI dengan link http://103.75.25.78/kpfti/. Apabila sudah dapat login maka aplikasi dapat diunduh dari halaman web KPFTI. Mengunduh aplikasi KPFTI juga dapat dilakukan dari link labira riset: http://103.75.25.78/labirariset/. Setelah mengunduh aplikasi tersebut dosen dapat menginstall aplikasi KPFTI dan membuka aplikasi KPFTI. Aplikasi dapat digunakan dengan melakukan login sesuai akun yang sudah dimiliki.

Dokumentasi dosen menggunakan program android dapat dilihat pada Gambar 11. Pada Gambar 11 dapat dilihat 2 orang dosen sedang mengakses aplikasi. Dosen menginput catatan sidang dan menandatangani nilai yang sudah di input ke dalam aplikasi pada saat sidang.
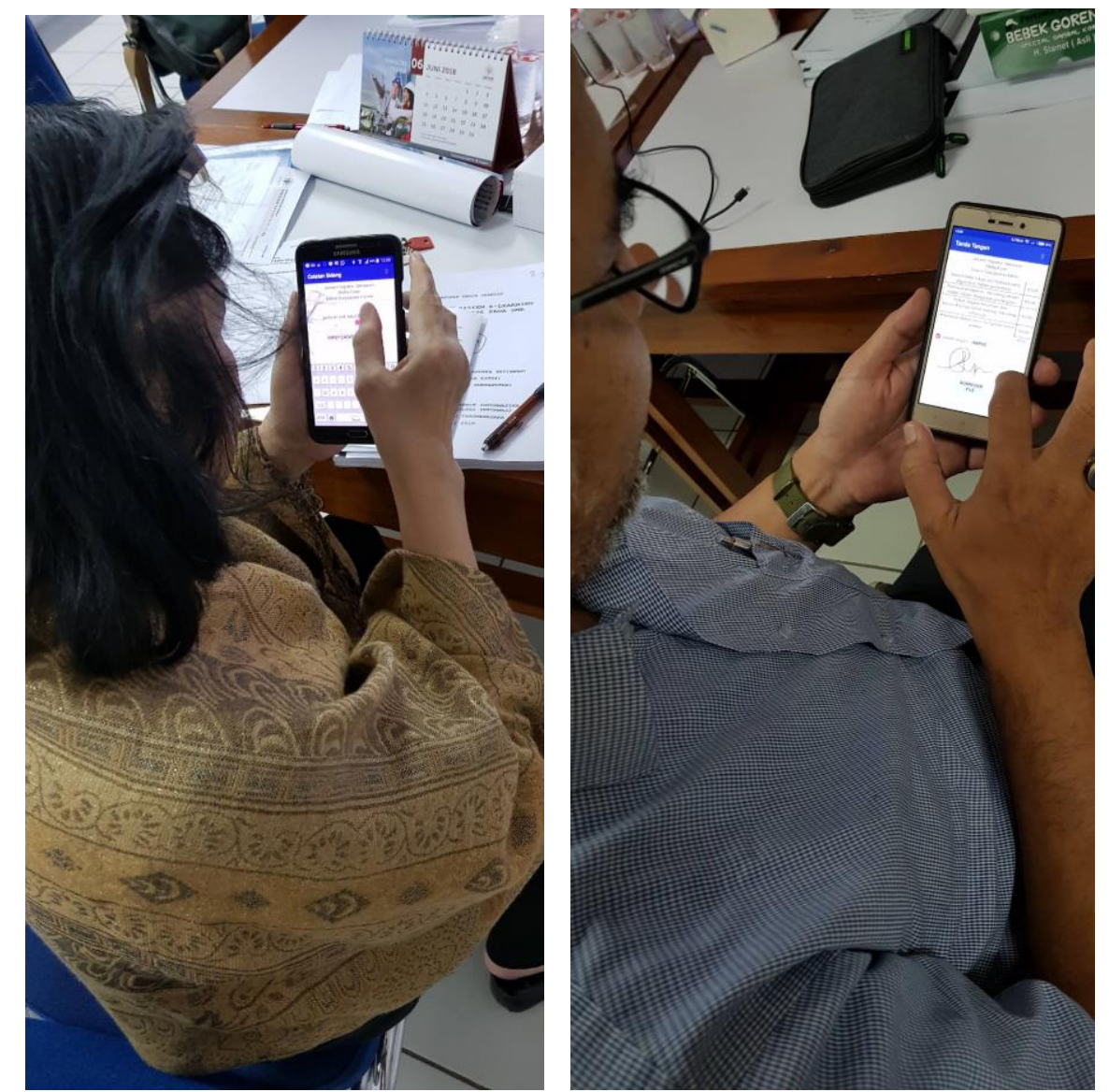

Gambar 11. Dokumentasi dosen sedang menggunakan aplikasi android

Setelah melakukan pengujian, implementasi ke server dan pelatihan kepada pengguna maka terdapat beberapa kendala yang muncul pada saat penggunaan aplikasi ini. Kendala tersebut sudah dapat diatasi pada saat proses testing dan implementasi. Kendala yang sudah dapat langsung diperbaiki adalah sebagai berikut:

1. Tampilan berantakan setelah rotate perangkat. Sudah diatasi dengan menambahkan code di android untuk mengatasi rotasi perangkat.

2. Menambahkan notifikasi pada perangkat android, jika ada penambahan pengumuman pada web kpfti. Selain itu, pada tampilan mahasiswa juga ditambahkan pengumuman. 
3. Menambahkan link/fungsi untuk download file pengumuman dan lowongan pada tampilan mahasiswa.

4. Apabila terjadi masalah dengan koneksi internet, hanya muncul tampilan kosong. Hal tersebut dikarenakan aplikasi menunggu 30 detik untuk terhubung ke server. Solusi dari permasalahan ini adalah ditambahkan penanda loading saat sedang mengambil data dari server.

5. Mahasiswa membutuhkan menu untuk menyimpan hasil catatan sidang. Solusinya adalah menambahkan fungsi pada mahasiswa untuk menyimpan catatan sidang ke dalam sebuah file text.

Walaupun terdapat beberapa kendala yang sudah dapat diatasi, masih terdapat kendala yang belum dapat diatas seperti belum ada fungsi untuk upload file yang terkait dengan pengumpulan berkas KP mahasiswa, hal ini hanya dapat dilakukan melalui web KPFTI untuk menghindari file yang terlalu besar ukurannya. Selain itu, perbedaan perangkat smartphone lainnya yang masih tidak mengalamai gangguan pada saat penggunaan aplikasi.

\section{KESIMPULAN DAN SARAN}

Pengabdian ini telah dilakukan oleh tim PKM selama 6 bulan. Proses pengabdian terdiri dari 2 tahap, tahap pertama adalah pembuatan program dan tahap kedua adalah pelatihan penggunaan program. Pengabdian ini telah menghasilkan produk aplikasi SIKP FTI berbasis android. Aplikasi ini telah digunakan pada saat sidang dan selanjutnya pada semester berjalan aplikasi ini akan digunakan secara berkelanjutan.

Saran terhadap pengabdian ini adalah membuat aplikasi pada platform lain seperti IoS agar dapat digunakan oleh pengguna yang tidak memiliki smartphone berbasiswa android. Selain itu melakukan pengujian terhadap jenis smartphone yang lebih beragam. Para pengguna juga berharap diberikan pelatihan kembali agar dapat lebih memahami penggunaan aplikasi SIKP FTI Untar ini.

\section{Ucapan Terima Kasih (Acknowledgement)}

Terima kasih kepada DPPM Untar yang telah membantu membiayai pengabdian ini. Terima kasih juga penulis ucapkan kepada pihak prodi, dosen dan mahasiswa yang ikut membantu dalam terwujudnya aplikasi sistem informasi KP FTI Untar ini.

\section{REFERENSI}

Kenneth E. Kendall and Julie E. Kendall, Systems Analysis and Design, 8th Edition, Upper Saddle River: Prentice Hall, 2006.

SPMI Kerja Praktik FTI Untar, 2017

Fakultas Teknologi Informasi Universitas Tarumanagara, Pedoman Pelaksanaan Dan Pembuatan Laporan Kerja Praktik, (Jakarta: FTI Universitas Tarumanagara, 2011)

Mawardi, Viny C., M., Bagus. dan H., Lely. Pembuatan dan Pelatihan Sistem Informasi Kerja Praktik Berbasis Web. Laporan PKM 2017. DPPM Untar. 